University of Nebraska - Lincoln

DigitalCommons@University of Nebraska - Lincoln

Papers in Plant Pathology

Plant Pathology Department

2003

\title{
Are Chlorella Viruses a Rich Source of Ion Channel Genes?
}

\author{
Ming Kang \\ University of Nebraska-Lincoln, mkang2@unl.edu \\ Anna Moroni \\ University of Milan, Italy \\ Sabrina Gazzarrini \\ University of Milan, Italy \\ James L. Van Etten \\ University of Nebraska-Lincoln, jvanetten1@unl.edu
}

Follow this and additional works at: https://digitalcommons.unl.edu/plantpathpapers

Part of the Plant Pathology Commons

Kang, Ming; Moroni, Anna; Gazzarrini, Sabrina; and Van Etten, James L., "Are Chlorella Viruses a Rich Source of Ion Channel Genes?" (2003). Papers in Plant Pathology. 212.

https://digitalcommons.unl.edu/plantpathpapers/212

This Article is brought to you for free and open access by the Plant Pathology Department at DigitalCommons@University of Nebraska - Lincoln. It has been accepted for inclusion in Papers in Plant Pathology by an authorized administrator of DigitalCommons@University of Nebraska - Lincoln. 


\title{
Are Chlorella Viruses a Rich Source of Ion Channel Genes?
}

\author{
Ming Kang, a Anna Moroni, b,c Sabrina Gazzarrini, ${ }^{\mathrm{b}}$ and James L. Van Etten ${ }^{\mathrm{a}, \mathrm{d}}$ \\ a Department of Plant Pathology, University of Nebraska-Lincoln, Lincoln, NE 68583-0722, USA \\ ${ }^{\mathrm{b}}$ Department of Biology and CNR-IBF, University of Milan, Via Celoria 26, 20133, Milan, Italy \\ c Istituto Nazionale Fisica Materia, Unità Milano-Università, Via Celoria 16, 20133, Milan, Italy \\ d Nebraska Center for Virology, University of Nebraska-Lincoln, Lincoln, NE 68588, USA \\ Corresponding author - J. L. Van Etten, fax 402 472-2853, e-mail jvanetten@unlnotes.unl.edu
}

\begin{abstract}
Plaque-forming dsDNA (>330 kb) viruses that infect certain unicellular, eukaryotic chlorella-like green algae contain $\sim 375$ protein-encoding genes. These proteins include a 94 amino acid $\mathrm{K}^{+}$channel protein, called $\mathrm{Kcv}$, as well as two putative ligand-gated ion channels. The viruses also encode other proteins that could be involved in the assembly and/ or function of ion channels, including protein kinases and a phosphatase, polyamine biosynthetic enzymes and histamine decarboxylase.
\end{abstract}

Keywords: $\mathrm{K}^{+}$channel, Kcv, Ligand-gated channel, Chlorella virus, PBCV-1

\section{Introduction}

Paramecium bursaria chlorella virus (PBCV-1) is the prototypic member of a group of large $(1900 \AA$ in diameter at the five-fold axis) icosahedral, plaque-forming, dsDNA viruses in the family Phycodnaviridae that replicate in certain unicellular, eukaryotic, chlorella-like green algae [1,2]. The sequence of the PBCV-1 $330 \mathrm{~kb}$ genome revealed an open reading frame (ORF) encoding a 94 amino acid (aa) protein that resembled two transmembrane domain (TM) $\mathrm{K}^{+}$channels. Similarities occurred in the putative TM topology and pore region connecting the two TM domains, as well as the selectivity filter signature sequence ThsTvGFG characteristic of $\mathrm{K}^{+}$channels. Peculiar to the PBCV-1 encoded protein, named Kcv, was the short 12 aa cytoplasmic N-terminus and the absence of a cytoplasmic C-terminus. Kcv basically consists of the 'pore module', TM-pore-TM structure common to all $\mathrm{K}^{+}$channels. $\mathrm{Kcv}$ is being intensively studied and some of its properties are discussed in two other manuscripts in this issue $[3,4]$.

This review will provide an overview of the chlorella viruses and then describe two other PBCV-1 ORFs that encode proteins that are predicted to have some properties characteristic of ligand-gated channels. Finally, we will mention some additional virus-encoded proteins that could either interact with or influence ion channel proteins.

\section{General properties of the chlorella viruses}

The chlorella viruses are included in the genus Chlorovirus that consists of three species. Viruses that infect Chlorella isolate NC64A (NC64A viruses) have been isolated from freshwater collected in the United States, South America, Australia, China, Japan, South Korea, Israel and Italy. Viruses that infect Chlorella Pbi (Pbi viruses) initially were discovered in freshwater collected in Europe [5], and more recently in water collected in Australia, Canada, and the northern United States as well as higher altitudes in the western United States (Nelson and Van Etten, unpublished results). Although the NC64A and Pbi viruses are morphologically, biologically and biochemically similar, two features distinguish them from one another: (i) viruses that infect Chlorella NC64A neither infect nor attach to Chlorella Pbi, and vice versa; (ii) the G+C content of the NC64A and Pbi virus genomes are about $40 \%$ and $46 \%$, respectively, indicating considerable evolutionary separation.

Chlorella NC64A and Chlorella Pbi are normally hereditary endosymbionts in green isolates of the protozoan $P$. bursaria. In the symbiotic unit, individual algae are surrounded by a host-derived membrane [6]. The endosymbiotic chlorella are resistant to virus infection and are only infected when they are separated from the protozoan $[7,8]$. Fortunately, both Chlorella isolates can be grown in the laboratory free of the paramecium and virus.

Members of the third species of Chlorovirus infect symbiotic chlorella in the coelenterate Hydra viridis [9]. These lytic viruses also have icosahedral morphology and large dsDNA genomes. However, the chlorella host has not been cultured free of the virus and consequently, the virus only can be isolated from chlorella cells freshly released from hydra.

Structurally, the chlorella viruses are complex and contain at least 50 different proteins; the most abundant protein is the major capsid glycoprotein Vp54. A lipid-containing membrane lies inside the outer capsid shell that is required for infectivity [10]. Chlorella virus genomes are linear molecules larger than $330 \mathrm{~kb}$ with terminal inverted repeats and covalently closed hairpin ends [11,12].

PBCV-1 infects its host chlorella by attaching rapidly to the external surface of the algal cell wall [13]. Attachment always occurs at a virus vertex and is followed by degradation of the 
host wall at the attachment point and entry of viral DNA and probably associated proteins (transcription factors?) into the cell. Circumstantial evidence indicates that the infecting virus DNA and probably DNA-associated proteins move to the nucleus where early transcription begins within 5-10 min post infection (p.i.). Virus DNA replication begins 60-90 min p.i., presumably in the nucleus, and is followed by transcription of late virus genes [14,15]. Progeny viruses are first released 4-5 $\mathrm{h}$ p.i., and the majority of infectious virus particles are released by $8 \mathrm{~h}$ p.i. by localized lysis of the cell wall.

Mechanical disruption of the cells releases infectious virus 30-50 min prior to spontaneous lysis. Consequently, infectious PBCV-1 is assembled inside the host and does not acquire its membrane and glycoprotein capsid by budding through the host plasma membrane.

\section{Chlorella viruses are probably very old}

Four observations indicate that the phycodnaviruses have a long evolutionary history. (i) Phylogenic analyses of DNA polymerases place the phycodnavirus enzymes near the root of all eukaryotic $\delta$ DNA polymerases [16,17]. (ii) Phylogenic analyses of many other PBCV-1 encoded proteins place the proteins near the base of the trees, e.g. the $\mathrm{K}^{+}$channel protein Kcv [18], the ornithine decarboxylase [19], and the GDPD-mannose 4,6-dehydratase (Duncan and Van Etten, unpublished results). (iii) Despite the fact that PBCV-1 encodes a mixture of prokaryotic- and eukaryotic-like proteins, the $\mathrm{G}+\mathrm{C}$ contents $(40 \%$ for PBCV-1) throughout its genome is reasonably uniform. This pattern suggests that most of the genes have existed in the virus for a long time. (iv) Some evolutionary biologists believe that the first eukaryotic cell resembled a unicellular green alga; consequently, if the chlorella viruses appeared and evolved with their hosts, their evolutionary history could date back more than 1.2 billion years (e.g. $[20,21])$. Taken together, these properties indicate that the phycodnaviruses and their genes have a long evolutionary history.

\section{PBCV-1 genome}

The $330 \mathrm{~kb}$ PBCV-1 genome encodes 700 ORFs of 65 codons or larger of which $\sim 375$ are probably protein-encoding; PBCV-1 also encodes 11 tRNA genes [2,22]. Of the 375 proteinencoding genes, $\sim 50 \%$ have been identified. PBCV-1 encodes more genes than any other known virus. To put the size of the PBCV-1 genome into perspective, the HIV virus that causes AIDS encodes about 12 genes, smallpox virus encodes about 180 genes, and the smallest self-replicating organism Mycoplasma genitalium, encodes about 470 proteins [23]. Estimates of the minimum genome size required to support life are $\sim 250$ protein-encoding genes [24,25].

In addition to their large genomes, the chlorella viruses have other distinctive features: (i) They encode multiple type II DNA methyltransferases and DNA site-specific (restriction) endonucleases. (ii) PBCV-1 is the first virus with more than one type of intron. The virus has three types of introns: a selfsplicing intron in a transcription factor TFIIS-like gene [26,27], a spliceosomal-processed intron in the DNA polymerase gene $[28,29]$, and a small intron in one of the tRNA genes [30]. (iii) Unlike other glycoprotein-containing viruses, PBCV-1 encodes most, if not all, of the components required to glycosylate its proteins.

(iv) Many PBCV-1 encoded enzymes are either the smallest or among the smallest proteins of their class and may represent the minimal catalytic unit. In addition, genes shared by chlorella virus isolates may differ in nucleotide sequence by as much as $40 \%$, which can translate into aa sequence differences of up to $30 \%$. Therefore, comparative gene sequence analyses can identify conserved aa in proteins, as well as regions that tolerate aa changes. The small sizes and the finding that many virus-encoded recombinant proteins are 'user friendly' in the laboratory have resulted in the biochemical and structural characterization of several PBCV-1 enzymes. Examples include: (a) The smallest known eukaryotic ATP-dependent DNA ligase [31], which is the subject of intensive mechanistic and structural studies ([32] and references cited therein). (b) The smallest known type II DNA topoisomerase [33]. The

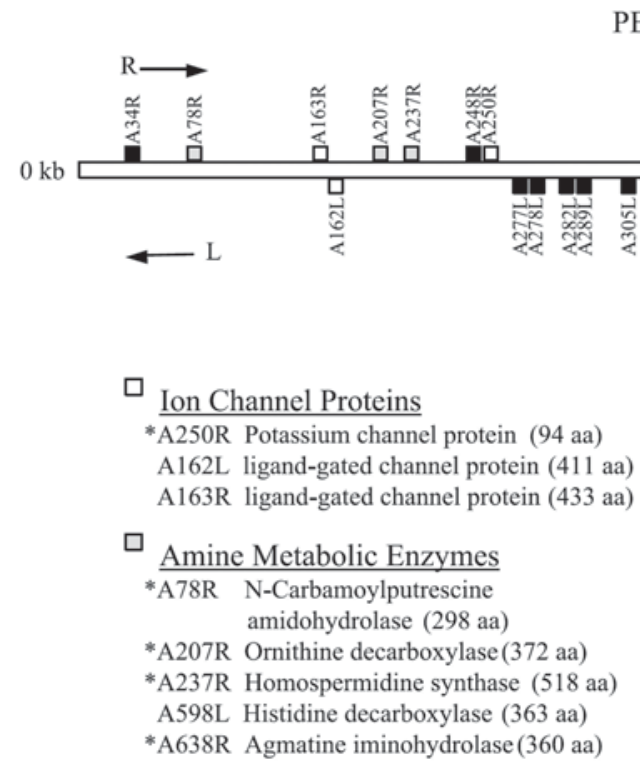

PBCV-1 Genome

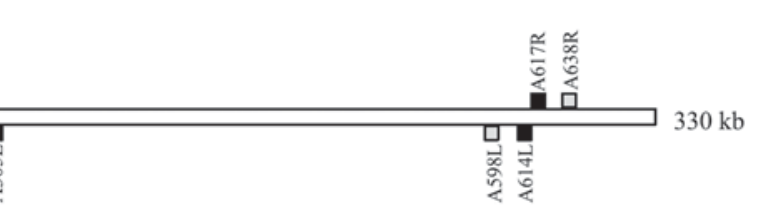

A 638 Rmatine iminohydrolase (360 aa)

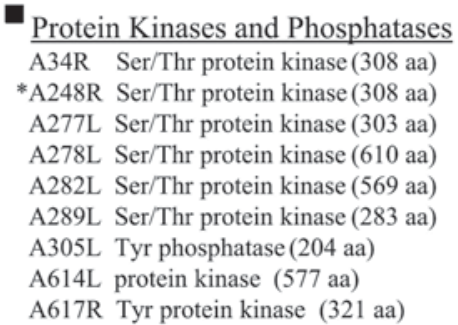

A617R Tyr protein kinase (321 aa)

Figure 1. Location of virus PBCV-1 genes encoding ion channel proteins and proteins that could influence ion channel function and/or assembly. An asterisk indicates the recombinant protein has the expected activity. The predicted numbers of aa in the proteins are in brackets. 


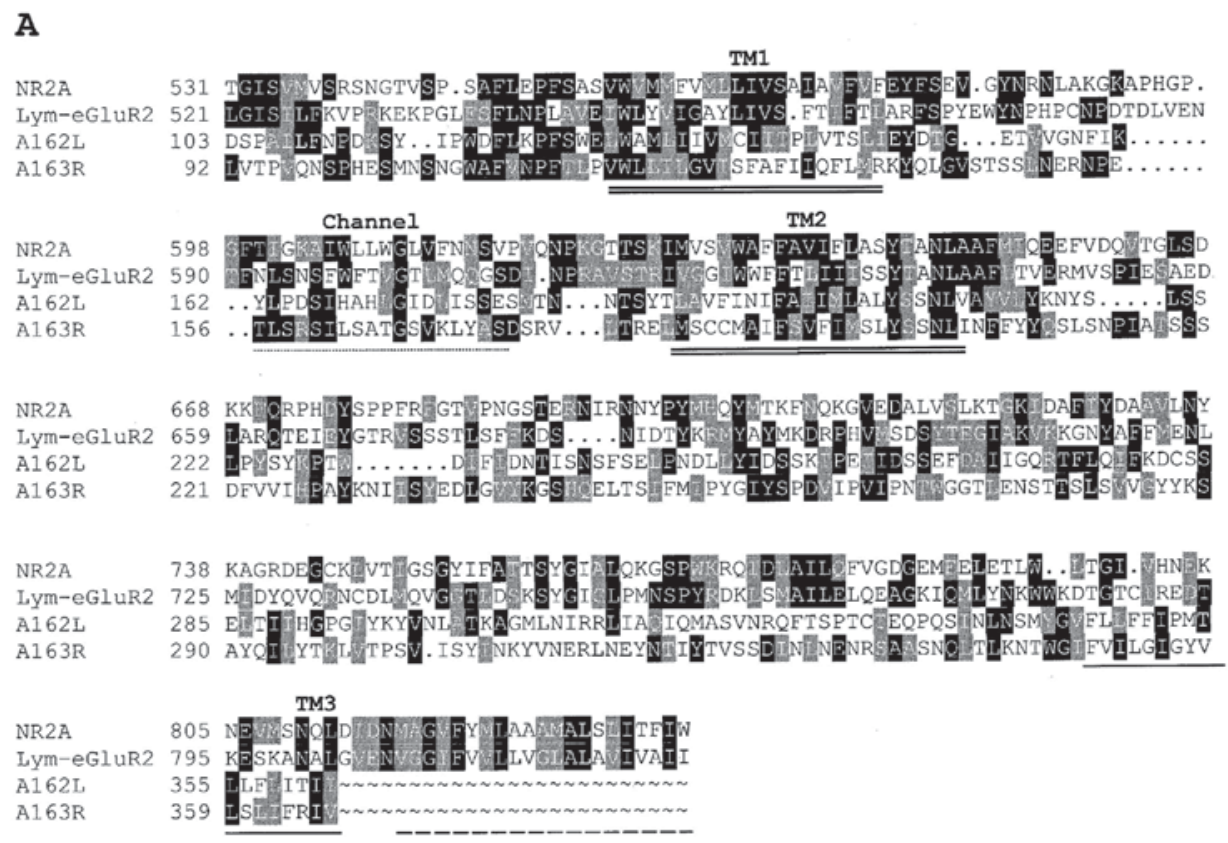

B

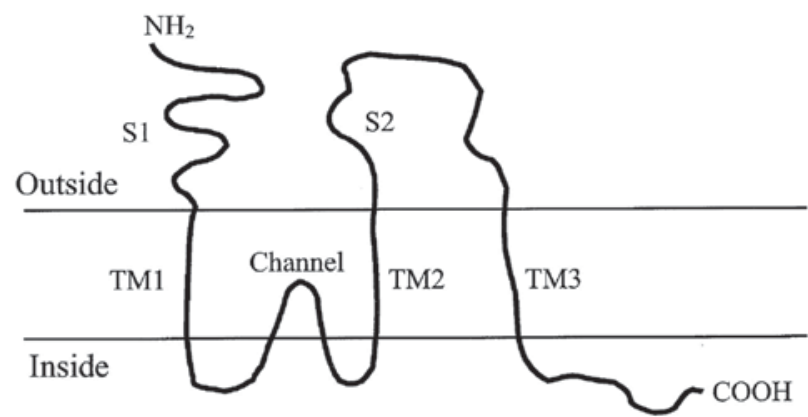

Figure 2. A: The alignment of two putative ligand-gated ion channel subunits from virus PBCV-1, A162L and A163R, an NMDA glutamate receptor channel subunit from human (NR2A) [54], and a kainate glutamate receptor channel subunit from Lymnaea stagnailis (Lym-eGluR2) [55]. Transmembrane domains 1 and 2 (TM1, TM2) in the four proteins are double underlined, the suspected channel regions among the four proteins are marked by square dots below the sequences, TM3 from the two PBCV-1 proteins are marked by a single underline, andTM3 from the two glutamate receptor channels are indicated by a dashed line. B: Putative topology of A162L and A163R proteins. The membrane topology was deduced from hydropathy analyses and the computer program HMMTOP 2.0. S1 and S2 domains could be involved in ligand binding.

PBCV-1 enzyme cleaves dsDNAs $\sim 30$ times faster than the human type II DNA topoisomerase [34,35]; consequently, the virus enzyme is being used as a model enzyme to study the topoisomerase II DNA cleavage process. (c) An RNA capping guanylyltransferase [36] that was the first enzyme of its type to have its crystal structure resolved [37]. (d) The smallest enzyme to post-translationally modify chromatin, a 120 aa protein that methylates histone $\mathrm{H} 3$ at $\mathrm{Lys}^{27}$ [38]. (e) The smallest known protein (94 aa) to form a functional $\mathrm{K}^{+}$channel [18].

More information, including a complete list of chlorella virus publications and additional images of the viruses, is available on the 'World of Chlorella Viruses' web page at: http:// www.ianr.unl.edu/plantpath/facilities/Virology.

\section{PBCV-1 encoded ligand-gated channels?}

PBCV-1 encodes two adjacent but divergent ORFs (A162L and A163R) that resemble ligand-gated ion channel proteins
(Fig. 1). The 411 codon A162L and 433 codon A163R proteins are predicted to have the three properly spaced TM domains typical of glutamate receptor ion channel proteins [39] (Fig. $2 \mathrm{~A})$. Furthermore, the computer program HMMTOP 2.0 predicts that the topology of the two viral encoded proteins resemble glutamate receptor proteins, the N-terminal residues reside outside the cell and the C-terminal residues reside inside the cell, as illustrated in Fig. 2B. Glutamate receptor channels mediate influx of cations $\left(\mathrm{K}^{+}, \mathrm{Na}^{+}\right.$, and $\left.\mathrm{Ca}^{2+}\right)$ across membranes $[39,40]$. However, the two PBCV-1 proteins, which have $21 \%$ aa identity with each other, lack recognizable glutamate binding sites.

A Northern blot of total RNAs isolated from uninfected and PBCV-1 infected chlorella was probed with ${ }^{32} \mathrm{P}-$ labeled ssDNA 'antisense' probes specific for a162l and a163r (Fig. $3)$. The $a 162 \mathrm{l}$ probe hybridizes to a single $\sim 1.7 \mathrm{~kb}$ RNA that first appears about 45 min p.i., reaches its highest level at 90 min p.i. and disappears between 180 and $240 \mathrm{~min}$ p.i. This size mRNA is sufficient to encode a protein of 411 aa. The $a 163 r$ 

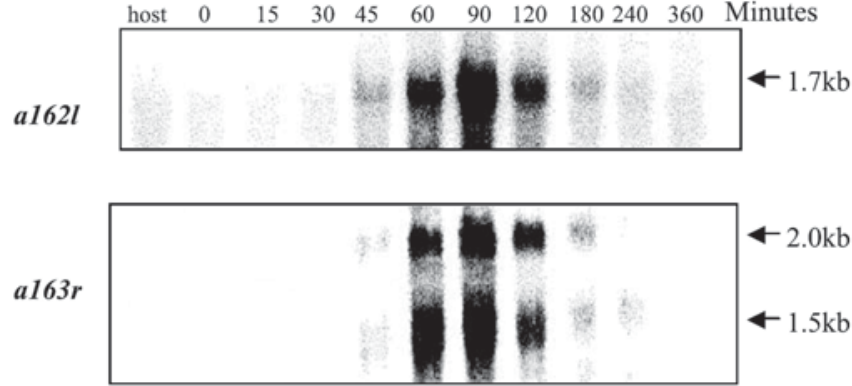

Figure 3. Transcription of PBCV-1 encoded putative ligand-gated ion channel genes $a 162 l$ and $a 163 r$. Total RNAs were isolatedfrom uninfected(host) and PBCV-1 infected Chlorella NC64A cells at the indicated time points ( $\mathrm{min}$ ) and hybridized with antisense ${ }^{32} \mathrm{P}-\mathrm{la}-$ beled a162l or a163r ssDNA probes.

probe hybridizes to two RNAs, one $\sim 1.5 \mathrm{~kb}$ and the other $\sim$ $2.0 \mathrm{~kb}$ (Fig. 3). Similar to $a 162 l$, a163r first appears between 45 and $60 \mathrm{~min}$ p.i., reaches its highest level at $60-90 \mathrm{~min}$ p.i. and disappears after $180 \mathrm{~min}$ p.i. Either mRNA is big enough to encode a protein of 433 aa.

The expression patterns of these two genes are unusual. PBCV-1 DNA replication begins between 60 and 90 min p.i. [15]. Typically, genes expressed prior to viral DNA replication are considered to be early genes and genes expressed after viral DNA begins are considered to be late genes. However, both $a 162 l$ and $a 163 r$ initiate transcription as late-early genes and continue to be expressed as late genes. It would be interesting to know if either or both proteins are synthesized and, if so, their intracellular location.

The two genes were cloned and cRNAs from both genes were injected together into Xenopus oocytes to test for channel activity. Using standard voltage clamp techniques, we looked for changes in macro-currents in response to $2 \mathrm{~s}$ voltage steps in the range +50 to $-160 \mathrm{mV}$. No differences in conductance were detected between control water-injected and cRNA-injected oocytes, even in the presence of $100 \mu \mathrm{M}$ glutamate. Also, removal of external $\mathrm{Mg}^{2+}$ and addition of polyamines (spermidine), which are known to modulate a-amino3-hydroxy-5-methyl-4-isoxazole proprionic acid (AMPA) and $\mathrm{N}$-methyl-D-aspartate (NMDA) glutamate receptor channels respectively, did not produce detectable currents.

There are several possible explanations for the lack of channel activity, including: (i) the genes do not encode ion channel proteins, (ii) the proteins are not embedded properly in the membrane, (iii) we did not use the proper ligand to activate the channels, or (iv) the experimental procedures were inappropriate for the respective channels. Perhaps checking for transient channel activity on a faster time-scale is required to detect these currents.

It is worth noting that the N-terminus of all eukaryotic glutamate receptors that have been expressed successfully in oocytes [41] contain a signal peptide of about 24 aa followed by a cleavage site. For example, GluR0, the first prokaryotic glutamate receptor channel (from cyanobacterium Synechocystis), could only be expressed in oocytes as a chimera; the N-terminal region containing the bacterial signal peptide was exchanged for the rat GluR6 signal sequence [42]. The respective signal peptide/cleavage site, which appears to be essential for expression in oocytes, is absent in A163R andA162L. Hence functional expression of these two viral proteins in oocytes may require a similar strategy.
Interestingly, plants encode $\sim 20$ genes with homology to animal glutamate receptor channels [43]. Although circumstantial evidence exists for their role in $\mathrm{Ca}^{+}{ }^{+}$homeostasis, signaling and morphogenesis $[44,45]$, none of these genes produce a functional channel in a heterologous expression system.

\section{Other PBCV-1 encoded proteins that could ef- fect channel function}

Other proteins or compounds often influence the assembly and/or function of ion channels including $\mathrm{K}^{+}$channels $[46,47]$. PBCV-1 contains several genes encoding proteins that could be involved in these processes: (i) Potassium channel activity is often modulated by phosphorylation and dephosphorylation [48] andPBCV-1 encodes eight putative protein kinases and one putative phosphatase. In fact, a Ser/Thr protein kinase gene is adjacent to the $\mathrm{K}^{+}$ion channel encoding gene in PBCV-1, as well as many other chlorella viruses (Kang et al., manuscript in preparation). (ii) PBCV-1 contains at least four genes that encode enzymes involved in polyamine biosynthesis, ornithine decarboxylase [19], homospermidine synthase [49], agmatine iminohydrolase and $N$-carbamoylputrescine amidohydrolase (Piotrowski, personal communication). Polyamines inhibit biological activity of Kir-type $\mathrm{K}^{+}$channels (e.g. [50-52]). (iii) PBCV-1 encodes a putative histidine decarboxylase. The product of histidine decarboxylase, histamine, is an important neurotransmitter of photoreceptors in insects and other arthopods [53]. As a photoreceptor transmitter in insects, histamine acts on ligand-gated chloride channels.

The connection, if any, between the putative PBCV-1 encoded protein kinases, polyamine biosynthetic enzymes, putative histidine decarboxylase, putative ligand-gated ion channel proteins and the $\mathrm{K}^{+}$channel protein is unknown. However, all of these components could be part of a regulated system for maintaining ionic balance and/or membrane potential within the chlorella during virus replication.

\section{Conclusions}

The chlorella viruses are unusual because they contain genes that encode several proteins that either form ion channels and/or have the potential to influence the activity of ion channels. Furthermore, because these viruses have been evolving for a very long time, they also provide a source of protein diversity. We encourage more people to study these viruses and their genes.

Acknowledgments: We thank Gerhard Thiel for his thoughtful comments on this manuscript. This investigation was supported in part by NIH Grant GM32441 to J.V.E.

\section{References}

[1]. J.L. Van Etten, L.C. Lane and R.H. Meints. Microbiol. Rev. 55 (1991), pp. 586-620.

[2]. J.L. Van Etten and R.H. Meints. Annu. Rev. Microbiol. 5 (1999), pp. 447-494.

[3]. Gazzarrini, S., Severino, M., Morandi, M., Lombardi, M., DiFrancesco, D., Van Etten, J.L., Thiel, G. and Moroni, A (2003) FEBS Lett. 552. 
[4]. Mehmel, M., Rothermel, M., Meckel, T., Howard, F., Van Etten, J.L., Moroni, A. and Thiel, G. (2003) FEBS Lett. (this issue).

[5]. W. Reisser, D.E. Burbank, S.M. Meints, R.H. Meints, B. Becker and J.L. Van Etten. Virology 167 (1988), pp. 143-149.

[6]. Reisser, W. (Ed.) (1992) Algae and Symbioses. Biopress, Bristol.

[7]. H. Kawakami and N. Kawakami. J. Protozool. 25 (1978), pp. 217-225.

[8]. W. Reisser, D.E. Burbank, R.H. Meints, B. Becker and J.L. Van Etten. Endocytobiosis Cell Res. 7 (1991), pp. 245-251.

[9]. J.L. Van Etten, R.H. Meints, D. Kuczmarski, D.E. Burbank and K. Lee. Proc. Natl. Acad. Sci. USA 79 (1982), pp. 3867-3871.

[10]. M.P. Skrdla, D.E. Burbank, Y. Xia, R.H. Meints and J.L. Van Etten. Virology 135 (1984), pp. 308-315.

[11]. J. Rohozinski, L.E. Girton and J.L. Van Etten. Virology 168 (1989), pp. 363-369.

[12]. Y. Zhang, P. Strasser, R. Grabherr and J.L. Van Etten. Virology 202 (1994), pp. 1079-1082.

[13]. R.H. Meints, K. Lee, D.E. Burbank and J.L. Van Etten. Virology 138 (1984), pp. 341-346.

[14]. A.M. Schuster, L. Girton, D.E. Burbank and J.L. Van Etten. Virology 148 (1986), pp. 181-189.

[15]. J.L. Van Etten, D.E. Burbank, J. Joshi and R.H. Meints. Virology 134 (1984), pp. 443-449.

[16]. Villarreal, L.P. (1999) in: Origin and Evolution of Viruses (Domingo, E., Webster, R., Holland, J.J., Pickett, T., Eds.), pp. 391-410, Academic Press, London.

[17]. L.P. Villarreal and V.R. DeFilippis. J. Virol. 74 (2000), pp. 7079-7084.

[18]. B. Plugge, S. Gazzarrini, M. Nelson, R. Cerana, J.L. Van Etten, C. Derst, D. DiFrancesco, A. Moroni and G. Thiel. Science 287 (2000), pp. 1641-1644.

[19]. T. Morehead, J.R. \Gurnon, B. Adams, K.W. Nickerson, L. Fitzgerald and J.L. Van Etten. Virology 301 (2002), pp. 165-175.

[20]. D.S. Heckman, D.M. Geiser, B.R. Eidell, R.L. Stauffer, N.L. Kardos and S.B. Hedges. Science 293 (2001), pp. 1129-1133.

[21]. Schopf, J.W. (1999) Cradle of Life. Princeton University Press, Princeton, NJ.

[22]. J.L. Van Etten, M.V. Graves, D.G. Müller, W. Boland and N. Delaroque. Arch. Virol. 147 (2002), pp. 1479-1516.

[23]. C.M. Fraser, J.D. Gocayne, O. White, M.D. Adams, R.A. Clayton, R.D. Fleischmann, C.J. Bult, A.R. Kerlavage, G. Sutton, J.M. Kelley, J.L. Fritchman, J.F. Weidman, K.V. Small, M. Sandusky, J. Fuhrmann, D. Nguyen, T.R. Utterback, D.M. Saudek, C.A. Phillips, J.M. Merrick, J.F. Tomb, B.A. Dougherty, K.F. Bott, P.C. Hu, T.S. Lucier, S.N. Peterson, H.O. Smith, C.A. Hutchison and J.C. Venter. Science 270 (1995), pp. 397-403.

[24]. M. Itaya. FEBS Lett. 362 (1995), pp. 257-260.

[25]. A.R. Mushegian and E.V. Koonin. Proc. Natl. Acad. Sci. USA 93 (1996), pp. 10268-10273.

[26]. Y. Li, Z. Lu, D.E. Burbank, G.F. Kutish, D.L. Rock and J.L. Van Etten. Virology 212 (1995), pp. 134-150.

[27]. T. Yamada, K. Tamura, T. Aimi and P. Songsri. Nucleic Acids Res. 22 (1994), pp. 2532-2537.

[28]. R. Grabherr, P. Strasser and J.L. Van Etten. Virology 188 (1992), pp. 721-731.
[29]. Y. Zhang, B. Adams, L. Sun, D.E. Burbank and J.L. Van Etten. Virology 285 (2001), pp. 313-321.

[30]. K. Nishida, T. Kawasaki, M. Fujie, S. Usami and T. Yamada. Virology 263 (1999), pp. 220-229.

[31]. C.K. Ho, J.L. Van Etten and S. Shuman. J. Virology 71 (1997), pp. 1931-1937.

[32]. V. Sriskanada and S. Shuman. Nucleic Acids Res. 30 (2002), pp. 903-911.

[33]. O.V. Lavrukhin, J.M. Fortune, T.G. Wood, D.E. Burbank, J.L. Van Etten, N. Osheroff and R.S. Lloyd. J. Biol. Chem. 275 (2000), pp. 6915-6921.

[34]. J.M. Fortune, O.V. Lavrukhin, J.R. Gurnon, J.L. Van Etten, R.S. Lloyd and N. Osheroff. J. Biol. Chem. 276 (2001), pp. 24401-24408.

[35]. J.M. Fortune, J.S. Dickey, O.V. Lavrukhin, J.L. Van Etten, R.S. Lloyd and N. Osheroff. Biochemistry 41 (2002), pp. 11761-11769.

[36]. C.K. Ho, J.L. Van Etten and S. Shuman. J. Virol. 70 (1996), pp. 6658-6664.

[37]. K. Hakansson, A.J. Doherty, S. Shuman and D.B. Wigley. Cell 89 (1997), pp. 543-553.

[38]. K.L. Manzur, A. Farooq, L. Zeng, O. Plotnikova, A.W. Koch, Sachchidanand and M.M. Zhou. Nat. Struct. Biol. 10 (2003), pp. 187-196

[39]. R. Dingledine, K. Borges, D. Bowie and S.F. Traynelis. Pharmacol. Rev. 51 (1999), pp. 7-61.

[40]. C. Miller. Neuron 25 (2000), pp. 7-9.

[41]. T. Stühmer, M. Amar, R.J. Harvey, I. Bermudex, J. van Minnen and M.G. Darlison. J. Neurosci. 16 (1996), pp. 2869-2880.

[42]. G.Q. Chen, D. Cui, M.L. Mayer and E. Gouauz. Nature 402 (1999), pp. 817-821.

[43]. B. Lacombe, D. Becker, R. Hedrich, R. DeSalle, M. Hollmann, J.M. Kwak, J.I. Schroeder, N. Le Novere, H.G. Nam, E.P. Spalding, M. Tester, F.J. Turano, J. Chiu and G. Coruzzi. Science 292 (2001), pp. 1486-1487.

[44]. K.L. Dennison and E.P. Spalding. Plant Physiol. 124 (2000), pp. 1511-1514.

[45]. E.D. Brenner, N. Martinez-Barboza, A.P. Clark, Q.S. Liang, D.W. Stevenson and G. Coruzzi. Plant Physiol. 124 (2000), pp. 1615-1624.

[46]. N. Dascal. Trends Endocrinol. Metab. 12 (2001), pp. 391-398

[47]. M.R. Hanlon and B.A. Wallace. Biochemistry 41 (2002), pp. 2886-2894

[48]. I.B. Levitan. Annu. Rev. Physiol. 56 (1994), pp. 193-212.

[49]. A. Kaiser, M. Vollmert, D. Tholl, M.V. Graves, W. Xing, A.D. Lisec, J.R. Gurnon, K.W. Nickerson and J.L. Van Etten. Virology 263 (1999), pp. 254-262.

[50]. E. Ficker, M. Taglialatela, B.A. Wible, C.M. Henley and A.M. Brown. Science 266 (1994), pp. 1068-1072.

[51]. T.I. Lin, H. Heider and C. Schroeder. J. Gen. Virol. 78 (1997), pp. 767-774.

[52]. A.N. Lopatin, E.N. Makhina and C.G. Nichols. Nature 372 (1994), pp. 366-369.

[53]. D.R. Nassel. Micros. Res. Tech. 44 (1999), pp. 121-136.

[54]. B. Le Bourdelles, K.A. Wafford, J.A. Kemp, G. Marshall, C. Bain, A.S. Wilcox, J.M. Sikela and P.J. Whiting. J. Neurochem. 62 (1994), pp. 2901-2908.

[55]. T. Stuhmer, M. Amar, R.J. Harvey, I. Bernudez, J.V. Minnen and M.G. Darlison. J. Neurosci. 16 (1996), pp. 2869-2880. 